\title{
A CENTRALIDADE DO TRABALHO NA MEDIDA SOCIOEDUCATIVA DE PRESTAÇÃO DE SERVIÇOS À COMUNIDADE
}

\author{
José Edson Martins \\ Universidade do Estado de Minas Gerais - UEMG - Brasil
}

\section{Resumo}

Nesse trabalho, pretende-se compreender e explicar a centralidade da categoria trabalho na medida de Prestação de Serviços à Comunidade (PSC). O estudo, com base exploratória e inserido no campo da pesquisa teórica apresenta, inicialmente, análise crítica da literatura nacional especializada. Posteriormente, a partir do pensamento marxista, reflete sob a centralidade do trabalho na medida de PSC. Por fim, analisa como se efetiva, por meio do trabalho, o caráter educativo dessa medida. Com base na pesquisa demonstra-se que o trabalho distingue a medida de PSC das outras medidas socioeducativas configurando sua forma peculiar de ser no campo jurídico e social.

Palavras-chave: Medida socioeducativa. Trabalho. Prestação de serviço à comunidade.

\section{Introdução}

Muito se debate, hoje em dia, sobre a redução da maioridade penal e as medidas socioeducativas aplicadas aos adolescentes autores de ato infracional ${ }^{1}$, porém a produção de conhecimento referente a medida de Prestação de Serviços à Comunidade (PSC) ${ }^{2}$ ainda é escassa e inexpressiva, conforme veremos abaixo. Para Ataíde (2002) não há um acúmulo de conhecimento por se tratar "[...] de uma medida, cuja aplicação, pode-se dizer, é ainda recente" (ATAÍDE,2002, p.15).

Utilizamos a internet como principal instrumento de pesquisa ${ }^{3}$ para mapear a literatura nacional. Posteriormente, classificamos para fins analítico a literatura nacional, localizada aqui, em seis (06) tipos de pesquisas. Não encontrei um tipo de pesquisa "puro ou ideal", ao contrário, quase todos os estudos sejam de forma pontual, secundário ou subtendido abordam,

\footnotetext{
${ }^{1}$ De acordo com o art. 103 do ECA/90 ato infracional é “[...] a conduta descrita como crime ou contravenção penal".

2 Conforme Prates (2012, p.73) “[...] alguns autores fazem menção à origem da prestação de serviço à comunidade como tendo surgido na legislação marítima sueca, que já em 1777, previa a substituição da pena pelo trabalho".

${ }^{3}$ Usamos dois critérios como parâmetro de seleção: o título do estudo deveria conter a expressão "prestação de serviço à comunidade" e a pesquisa deveria se referir a medida socioeducativa aplicada a adolescentes, ao invés, da pena alternativa de prestação de serviços à comunidade aplicada a adultos.
} 
em menor grau ou maior, as problemáticas pesquisadas em outros estudos. Considerando isso, agrupou-se os estudos a partir da principal problemática investigada.

O primeiro tipo, representado por Silva \& Torres (2011) e Freitas (2014), estuda o perfil dos adolescentes sendo pesquisas corriqueiras no universo das medidas socioeducativas. Esses perfis, construídos por meio de pesquisas quantitativas, delineiam os adolescentes criando, desse modo, representações fragmentadas deles sem estabelecer as devidas relações ou conexões entre essas representações. Além disso, capturam as formas, as representações, mas não o conteúdo, isto é, as determinações sociais, políticas e econômicas que engendraram tais perfis. Já o segundo tipo de pesquisa investiga as causas e os motivos para prática de atos infracionais. Aparece de forma pontual em várias pesquisas, porém somente Gonçalves (2002) aborda o tema como objeto de estudo. O autor não investiga a causa para prática de atos infracionais no movimento contraditório do sistema capitalista detendo-se em analisar apenas a existência imediata desse movimento tomando-o como causa, ao invés de consequência.

Craidy \& Gonçalves (2005), Vital (2005), Prates (2012) ${ }^{4}$, Ataíde (2002) e Santos (2009) estudam o impacto, a efetividade e eficiência da medida de PSC. Tais estudos criam a impressão que os resultados obtidos na execução dessa medida dependem somente da forma de execução e operacionalização da medida ignorando, assim, as determinantes sociais, econômicas e históricas que condicionam tais resultados. Outro grupo de estudiosos, formados por Silva, L. (2009), Gobbo \& Muller (2009) e Santana (2009), investigam a natureza socioeducativa da PSC. Pensam o caráter educativo ou punitivo da medida a partir, principalmente, do trabalho desenvolvido pelos adolescentes durante o cumprimento da medida, no entanto não diferenciam o trabalho pedagógico de outro não pedagógico nem explicam o que faz o trabalho adquirir caráter educativo ou punitivo dentro da medida de PSC.

Silveira (2005), Miyagui (2008) e Costa \& Alípio (2010), por outro lado, deslocam a problemática do campo das causas, dos resultados, das possibilidades e limites da efetivação do caráter sociopedagógico para o campo das significações e sentidos atribuídos a essa medida socioeducativa. Para os autores as significações atribuídas a medida pelos adolescentes são produtos puramente subjetivos, desta forma, ignoram que as representações e significações, também, são expressões de construções históricas e sociais internalizadas pelos

\footnotetext{
${ }^{4}$ A primeira edição dessa obra foi publica, em 2001, sendo da literatura localizada aqui a primeira pesquisa, no Brasil, a abordar a medida de PSC como objeto de estudo.
} 
indivíduos e externalizadas juntamente com suas experiências existenciais. Por último, Pôssa (2013, p. 08) ao buscar "[...] responder como o cumprimento da medida socioeducativa de PSC acontece no interior das escolas da rede municipal" (PÔSSA, 2013, p. 08) de Belo Horizonte/MG insere uma nova problemática no campo dos estudos da PSC. O lócus no qual se efetiva a prestação de serviço à comunidade, por meio do trabalho comunitário, é tomado como objeto de estudo nessa pesquisa.

Até hoje, esses relevantes estudos no campo socioeducativo, com raras exceções, levantaram questões e pesquisaram problemáticas comuns a toda as medidas socioeducativas de meio fechado e aberto. Detiveram-se a discussões gerais e transversais a todas as medidas e, por conseguinte, estudaram a existência imediata da PSC enquanto forma genérica das medidas socioeducativas, porém não investigaram o que distingue a PSC das outras medidas ou lhe atribui características especificas. Busca-se aqui, justamente, investigar a especificidade, sendo os estudos, citados acima, o substrato material a partir do qual será pensada a categoria trabalho na medida socioeducativa de PSC.

Exposto isso, o artigo $^{5}$ procura compreender a centralidade do trabalho na medida de Prestação de Serviços à Comunidade. Esse estudo exploratório insere-se no campo da pesquisa teórica e apresenta, inicialmente, análise crítica da literatura nacional especializada. Posteriormente, a partir do pensamento Marxista e observações de casos concretos ${ }^{6}$, vivenciados no Serviço de Proteção Social a Adolescentes em Cumprimento de Medidas Socioeducativas de Prestação de Serviços à Comunidade (PSC) e Liberdade Assistida (L.A) da Prefeitura Municipal de Belo Horizonte/MG, reflete-se sob a categoria trabalho nessa medida socioeducativa. Por fim, analisa-se como o trabalho contribui para efetivação do caráter educativo dessa medida.

A abordagem desse tema apesar da sua importância para melhor compreensão da medida de PSC, até hoje, tem sido tratada de forma secundária pela literatura especializada. Em razão disso, as reflexões sob a categoria do trabalho na medida de PSC vêm sendo marcadas muito mais por enganos do que por acertos como será visto. Por isso, esse artigo poderá contribuir para avanços nos debates no campo socioeducativo.

\footnotetext{
${ }^{5}$ Dedico esse artigo aos adolescentes autores de ato infracional que ao infringirem a lei nos levam a refletir sob a sociedade que as legitima e aos Analistas de Políticas Públicas do Município de Belo Horizonte/MG, em especial os Analistas do CREAS da regional Centro-sul, com os quais tive o prazer de trabalhar e conviver.

${ }^{6}$ Entendemos aqui o concreto como "[...] a síntese de muitas determinações, isto é, unidade do diverso. Por isso o concreto aparece no pensamento como o processo da síntese, como resultado, não como ponto de partida, ainda que seja o ponto de partida efetivo e, portanto, o ponto de partida também da intuição e da representação" (MARX, 1978, p. 116).
} 


\section{Os Significados da Prestação de Serviços à Comunidade}

No Brasil ${ }^{7}$, a medida socioeducativa de Prestação de Serviços à Comunidade (PSC) surge no campo do direito infanto-juvenil com a promulgação do Estatuto da Criança e do Adolescente (ECA), em 1990. Anterior a sua promulgação o Código de Menores de 1972 regulamentava as sanções em caso de violação da lei por parte de menores de idade, mas “"[...] não previa a medida socioeducativa de Prestação de Serviço à Comunidade, limitando-se à Liberdade Assistida, à Privação da Liberdade e à Semiliberdade” (ATAÍDE, 2002, p. 15).

Com o ECA/90 essa medida se insere no contexto da municipalização do atendimento, conforme artigo 88, inciso I desta lei. A partir da Política Nacional de Assistência Social (PNAS, 2004), a Tipificação Nacional de Serviços Socioassistênciais (2009) e o Sistema Nacional de Atendimento Socioeducativo (SINASE/2012) ${ }^{8}$ adquire diretrizes mais claras e ganha certa padronização no território nacional.

Já do ponto de vista jurídico, a Prestação de Serviços à Comunidade faz parte do rol das medidas socioeducativas aplicadas ao adolescente por autoridade judicial competente comprovado a autoria de ato infracional (ECA,1990, art.114). Conforme o ECA/90, a “[...] prestação de serviços comunitários consiste na realização de tarefas gratuitas” (ECA, 1990, art. 117) em instituições sem fins lucrativos: hospitais, escolas, entidades assistenciais e outras instituições congêneres, assim como programas comunitários e governamentais por período máximo de 06 meses/08 horas semanais podendo ser realizado aos sábados, domingos, feriados ou em dias úteis de modo a não prejudicar a frequência à escola nem à jornada de trabalho.

À primeira vista o termo prestação de serviços à comunidade parece simples tautologia, visto que todo trabalho ou serviço prestado é a comunidade para atender às suas necessidades sociais construídas historicamente. Se pensarmos, nesses termos, o adolescente teria a possibilidade de cumprir a medida de PSC em qualquer instituição, já que uma unidade de saúde pública presta um serviço à comunidade, assim como, uma unidade de saúde privada. No entanto, tal hipótese não se confirma na prática, uma vez que o cumprimento da medida se limita a instituições sem fins lucrativos. Percebe-se, portanto, que o termo comunidade aqui diz mais do caráter econômico da prestação de serviços que da própria comunidade, isto é, um grupo de pessoas que vivem em determinado território e estão ligadas por uma história conjunta, tradições, crenças, costumes e valores.

\footnotetext{
${ }^{7}$ Nas palavras de Prates (2012, p.74) “[...] no Brasil, iniciou-se uma movimentação em favor da medida de prestação de serviços à comunidade, no I Encontro Penitenciários, em 1971".

${ }^{8}$ O SINASE existe desde 2006 enquanto conjunto de normas, princípios e critérios para execução das medidas socioeducativas, mas se tornou lei somente em 2012.
} 
Essa mudança do ponto de vista do destinatário da prestação (comunidade) para o econômico faz a aparente redundância desaparecer. O significado de comunidade, nessa perspectiva, inscreve-se na e a partir da dicotomia entre a prestação de serviços públicos sem fins lucrativos e a prestação de serviços privados com fins lucrativos. As atividades sem fins lucrativos, por um lado, aparecem como públicas e, por conseguinte, comunitárias enquanto, por outro lado, as com fins lucrativos aparecem como ações privadas e, consequentemente, não comunitárias.

Desta forma, relega a um segundo plano não só a comunidade, no sentido sociológico, mas também o território ocupado por determinada comunidade. Com isso quando, por exemplo, um determinado adolescente ao cumprir essa medida no Programa de Medida de PSC da UFGS desempenhando atividades de digitação, arquivamento de documentos e outras atividades (GONÇALVES, 2002) deverá ser considerado membro da comunidade acadêmica dessa universidade ou estranho ${ }^{9}$ Presta um trabalho comunitário para estranhos ou para sua comunidade?

Já em relação ao termo prestação de serviços apresenta uma dupla significação: do ponto de vista socioeducativo designa uma medida judicial aplicada a determinado adolescente como resposta Estatal ao cometimento de um ato infracional. Enquanto do ponto de vista econômico, expressa a diferença da produção de um bem ou de um produto, visto que “[...] serviço é trabalho em processo, e não o resultado da ação do trabalho; por esta razão elementar, não se produz um serviço, e sim presta um serviço" (MEIRELLES, 2006, p. 134).

Geralmente, essas duas concepções entrelaçam-se e confundem-se na execução dessa medida. Não raras vezes ouvimos dizer que determinado adolescente autor de ato infrator presta serviços à comunidade (ATAÍDE, 2002; COSTA \& ALÍPIO, 2010). Afinal, presta que tipo de serviço? Para ser um prestador de serviços necessita preencher alguns pré-requisitos básicos: qualificação profissional em determinada área colocando tal conhecimento a disposição de um terceiro contratante, ser proprietário dos instrumentos de trabalho, não ser assalariado e ter liberdade para organizar o processo de trabalho.

É evidente que o adolescente não preenche tais requisitos e, logo, não presta nenhum serviço à comunidade. Na verdade, quem presta algum serviço, seja na área da educação, na cultura, no esporte ou outra área, é a instituição criada para tal finalidade imaginar o oposto seria mistificar tal fato. Deste modo, ao ser encaminhado a determinada instituição para cumprimento da medida de

\footnotetext{
9 Para um orientador entrevistado por Santana (2009, p.63) “[...] a PSC é uma oportunidade para os meninos verem que existe outro mundo, ver que o mundo não é só ali onde eles moram e as pessoas que eles convivem, porque queira ou não, aqui [UFGS] o ambiente é diferente, as pessoas são diferentes".
} 
PSC insere-se no processo de trabalho de prestação de serviços como força de trabalho. ${ }^{10}$ Não coloca à disposição da instituição um serviço como pensam alguns autores, mas a sua força de trabalho. Para Marx (1982), nesse sentido, a força de trabalho é “[...] o conjunto das faculdades físicas e mentais, existentes no corpo e na personalidade viva de um ser humano, as quais ele põe em ação toda a vez que produz valores de uso de qualquer espécie" (MARX,1982, p. 85).

Participa, desta forma, do processo de prestação de serviços como trabalhador, mas não só como trabalhador, participa também como socioeducando cumprindo uma determinação judicial. É trabalhador por força da lei, por violação da lei. A medida socioeducativa, nessas circunstâncias, o faz trabalhador, porém não trabalhador autônomo ou assalariado, o faz trabalhador socioeducando que não só se educa com e pelo trabalho, mas também recompensa a sociedade o ato ilícito, a violação do pacto social, com e pelo trabalho.

\section{O Trabalho na Prestação de Serviços à Comunidade}

Independente da época ou lugar o homem precisa relacionar-se com a natureza, uma vez que "[...] a natureza é o corpo inorgânico do homem com o qual ele tem de ficar num processo contínuo para não morrer" (MARX, 2004, p. 84). O homem, nessa relação, cria as bases matérias para existência humana ao apropriar, por meio do trabalho, de modo consciente da natureza exterior modificando-a e submetendo-a a sua vontade para satisfazer as suas necessidades fisiológicas e sociais.

Os homens não estão sozinhos nesse processo de modificação da natureza, pelo contrário, estabelecem entre si relações sociais de produção fundadas na cooperação ou exploração dependendo do modo de produção (HARNECKER, 1971). Não só a natureza dessas

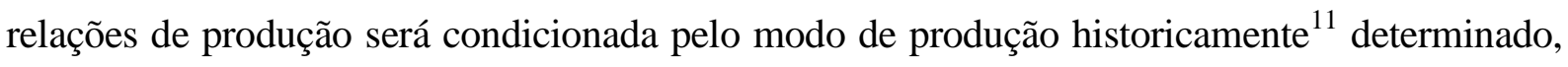
mas também toda a vida social, visto que "[...] o modo de produção da vida material condiciona o processo da vida social, política e espiritual” (MARX, apud HARNECHER, 1971, p. 133). O modo de produção capitalista vigente, nessa concepção, engendra uma estrutura social fundamentada na propriedade privada e, consequentemente, na exploração. É justamente, nessa sociedade capitalista, que a Prestação de Serviços à Comunidade (PSC), enquanto medida socioeducativa, se insere e, portanto, também se subordina à lógica capitalista. A partir desse pressuposto,

\footnotetext{
${ }^{10}$ Nesse sentido uma diretora disse que "[...] observei na unidade que conhece que o adolescente entra [na instituição de cumprimento da PSC] como mão-de-obra, para suprir, para somar no quadro de funcionários" (SANTANA, 2009, p. 57).

${ }^{11}$ Nessa concepção, Marx (2004, p. 204) afirma que “[...] o que distingue épocas econômicas não é o que se faz, mas como, com que meios de trabalho se faz".
} 
abaixo busca-se compreender a centralidade do trabalho dentro da medida de PSC sem, no entanto, esgotar todo tema aqui.

Aquilo que torna cada medida única e, por conseguinte, as diferenciam não nega o que as tornam iguais e imprime-lhes unidade. O caráter educativo e punitivo das medias socioeducativas confere-lhes unidade, todavia em cada uma dessas medidas há um determinado elemento precípuo que não só condiciona a sua operacionalização, mas também delimita suas características e forma de ser no mundo jurídico e social. Tal elemento cria condições para diferenciarem-se umas das outras e formarem uma identidade própria enquanto medida socioeducativa especifica, mas que conservam, ao mesmo tempo, a unidade.

O trabalho, nessa concepção, dá a medida de PSC identidade própria no campo socioeducativo. Não só distingue a PSC das outras medidas, mas também a liga diretamente às ideias em torno do mundo do trabalho não sendo possível pensá-la dissociada destas. O próprio nome dessa medida socioeducativa induz a quiproquó: a medida de PSC é trabalho ou vice-versa levando, muitas vezes, a serem tratadas como coisas de mesma natureza ou propriedade, embora sejam coisas distintas. O trabalho, por um lado, faz parte da medida de PSC que não se esgota ou resume-se ao trabalho, por outro lado, também não se restringe a tal medida ocupando um papel central na sociedade ao produzir a vida material que assegura a existência humana.

Apreender, por isso, o trabalho no âmbito do PSC somente pelo ponto de vista econômico seria ignorar as marcas impressas pelo ECA/90 e SINASE/2012 nesse trabalho, mas compreendê-lo somente pelo ponto de vista socioeducativo, também, seria imaginá-lo desconectado de um processo de trabalho inserido dentro do modo de produção capitalista. O fato desse trabalho se metamorfosear em determinação judicial não anula nem nega o fato desse trabalho se efetivar em uma sociedade organizada a partir do modo de produção capitalista. Porém, não podemos negar que as prescrições, principalmente, do ECA/90 condicionam a objetivação do trabalho no âmbito da PSC, como por exemplo, a limitação da carga horária.

O trabalho encontra-se, assim, permeado e entrelaçado indissociavelmente por elementos do campo socioeducativo (responsabilização, mínima intervenção do Estado, etc.) e por elementos do modo de produção capitalista (trabalho assalariado, divisão social do trabalho, apropriação privada da produção, etc.) sendo condicionado, ${ }^{12}$ em última instância, pelo sistema de produção capitalista. Por essa razão, o trabalho deve ser compreendido aqui a partir do entrelaçamento entre o campo socioeducativo e o sistema de produção capitalista.

\footnotetext{
${ }^{12}$ Para Engels, apud Harnecker (1971, p.96), “[...] o desenvolvimento político, jurídico, filosófico, religioso, literário, artístico etc, descansa no desenvolvimento econômico. Mas todos eles também repercutem uns sobre os outros e sobre a base da necessidade econômica que se impõe sempre, em última instância".
} 


\section{A Natureza do Trabalho Comunitário}

A inserção do adolescente na instituição, por um lado, acontece por força da lei não pela compra de sua força de trabalho no mercado como acontece com o trabalhador assalariado. $\mathrm{O}$ direito da utilização da força de trabalho nasce no campo do direito penal fora da esfera do mercado e circulação de mercadorias, por isso as instituições nada pagam pela força de trabalho. Por outro lado, o trabalho do adolescente socioeducando não cria valor para instituição, ou melhor, sua força de trabalho ao ser consumida em um processo de trabalho sem fins lucrativos, logo é trabalho improdutivo, todavia colabora para manutenção e reprodução do capital.

Para Marx (1996, p. 138) “[...] apenas é produtivo o trabalhador que produz mais-valia para o capitalista ou serve à autovalorização do capital”, visto que “[...] o trabalhador produz não para si, mas para o capital. Não basta, portanto, que produza em geral. Ele tem de produzir mais-valia" (MARX, 1996, p. 138). Ainda nessa linha de pensamento o autor destaca que:

O conceito de trabalho produtivo, portanto, não encerra de modo algum apenas uma relação entre a atividade e efeito útil, entre trabalhador e produto do trabalho, mas também uma relação de produção especificamente social, formada historicamente, a qual marca o trabalhador como meio direto de valorização do capital (MARX,1996, p. 138).

Os adolescentes são indiferentes a natureza produtiva/improdutiva do trabalho nessa medida socioeducativa, mas geralmente questionam o caráter gratuito do trabalho na medida de PSC. A natureza gratuita do trabalho aflora sentimentos de insatisfação (CRAIDY; GONÇALVES, 2005) e indignação nos adolescentes, geralmente, pertencentes a classe trabalhadora ${ }^{13}$ e moradores da preferia. ${ }^{14}$ Tais queixas devem ser compreendidas aqui duplamente: primeiro, como uma forma de resistência a lei e ao imperativo trabalhe imposto pela lei, uma vez que negar tal imperativo é negar o cumprimento dessa medida.

Segundo, questionam o caráter gratuito a partir da concepção de trabalho assalariado peculiar a sociedade capitalista que pressupõe a força de trabalho como mercadoria passível de ser trocada no mercado por determinada quantia de dinheiro necessária a (re) produção do trabalhador. Se, por um lado, o "[...] operário só recebe o seu salário depois de realizar o seu trabalho" (MARX, 1978, p. 84), por outro lado o adolescente só conquista o direito de permanecer em liberdade trabalhando gratuitamente. Se no primeiro o dinheiro é a mercadoria de troca, no segundo é a liberdade. Costa \& Alípio (2010), em razão disso, observaram que na medida de

\footnotetext{
${ }^{13}$ Santos (2009, p.40) observa que os adolescentes em cumprimento de PSC geralmente advêm de famílias pertencentes a classe trabalhadora.

${ }^{14}$ Para Gonçalves (2002, p.111) a maioria dos jovens atendidos no programa de PSC da UFRGS moram na periferia.
} 
PSC o trabalho para maioria dos adolescentes “[...] não é considerado como trabalho, mas somente como um cumprimento de determinação judicial" (COSTA \& SILVA, 2010, p. 205) sendo considerado, pelos adolescentes, como trabalho somente a atividade assalariada.

Tal fato leva o adolescente a questionar o trabalho não pago na medida de PSC, mas a partir disso não toma consciência que, também, nada recebe por uma parte do trabalho assalariado. Para Marx (1978, p. 84) “[...] dentro do sistema do assalariado até o trabalho não remunerado parece trabalho pago", uma vez que o trabalhador "[...] imagina que o valor ou preço de sua força de trabalho é o preço ou o valor do seu próprio trabalho" (MARX, 1978, p. 84). Ainda, nessa linha de pensamento, no que diz respeito à diferença entre o trabalho pago e não pago no modo de produção capitalista, Marx (1978) coloca que:

Comparando o processo de produzir valor com o de produzir mais valia, veremos que o
segundo só difere do primeiro por se prolongar além de certo ponto. O processo de
produzir valor simplesmente dura até o ponto em que o valor da força de trabalho pago
pelo capital é substituído por um equivalente. Ultrapassando esse ponto, o processo de
produzir valor torna-se processo de produzir mais-valia (valor excedente) (MARX, 1978,
p. 219).

Contudo, o caráter gratuito da força de trabalho durante o cumprimento da medida de PSC não transforma o adolescente em trabalhador voluntário ou o reveste com tais características. Santos (2009, p. 128), nesse ponto, destaca que “[...] o trabalho gratuito muitas vezes é vinculado pela sociedade como trabalho voluntário do adolescente em sua comunidade. Esta visão também faz parte da percepção do adolescente".

Trabalha por força da lei, por coação judicial não por vontade própria ou princípios religiosos e humanitários. Logo, raras exceções, ao cessa a determinação judicial cessa o trabalho, já que assim como o proletariado "[...] o trabalho não é a satisfação de uma carência, mas somente um meio para satisfazer necessidades fora dele" (MARX, 1994, p. 83). Se, por um lado, o trabalho do proletariado satisfaz a necessidade de acumulação do capital, por outro lado, o trabalho do adolescente socioeducando satisfaz a necessidade da sociedade de punir $^{15}$ os desvios de conduta dos jovens infratores e de ajustar os "desajustados" as normas sociais vigentes. Por isso, o estranhamento em relação a sua atividade leva a ambos a "[...] só se sente, por conseguinte, e em primeiro lugar, junto a si [quando] fora do trabalho e fora de si [quando] no trabalho" (MARX, 1994, p. 83).

\footnotetext{
${ }^{15}$ Conforme Liberati (1996, p.36) “[...] na verdade, a citada lei [ECA/90] não pretendeu dar caráter sancionatório punitivo-retributivo às medidas socioeducativas; porém, outro significado não lhes pode ser dado, vez que estas correspondem à resposta do Estado à prática de ato infracional e, por isso, assumem o caráter de inflição/sanção, a exemplo das penas, e não de prêmio".
} 
Embora exista controvérsias, diante do exposto acima, o trabalho na medida de PSC só pode ser pensado como trabalho forçado revestido de finalidade pedagógica. A convenção sobre o trabalho forçado ou obrigatório (1932, art.2) definiu trabalho forçado como "[...] todo trabalho ou serviço exigido de uma pessoa sob a ameaça de sanção e para o qual não se tenha oferecido espontaneamente", com exceção, de qualquer trabalho ou serviço imposto a uma pessoa em razão de condenação judicial. Ainda nesse sentido, Ferreira (2006) afirma que no Brasil:

\begin{abstract}
A Constituição Federal estabelece a proibição de pena relativa a trabalhos forçados (art. $5^{\circ}$, XLVII, "c") e o ECA, seguindo tal determinação, proibiu a prestação de trabalho forçado como medida socioeducativa (art. 112, parágrafo $2^{\circ}$ ). Essa proibição guarda relação direta com a medida de prestação de serviços à comunidade, que consiste na realização de tarefas gratuitas e de interesse geral, compatíveis com as aptidões físicas e intelectuais do adolescente e sua condição social, mas nunca de trabalho forçado. $\mathrm{O}$ trabalho a ser por ele desenvolvido deve ter caráter educativo e socializante (FERREIRA, 2006, p. 404).
\end{abstract}

A lei ao negar, no entanto, no plano simbólico o caráter forçado desse trabalho não altera na prática sua natureza ou sua forma de ser, uma vez que atribuir-lhe significado diferente não muda suas propriedades concretas e forma de objetivação na vida cotidiana. Mesmo que o trabalho desenvolvido pelo adolescente leve em consideração suas habilidades, aptidões e tenha finalidade educativa não o torna diferente, já que as condições concretas que o sustenta caracteriza seu caráter obrigatório ${ }^{16}$ cuja manifestação dá-se pela coação para trabalhar ou sanção ${ }^{17}$ caso não trabalhe.

A utilização dessa força de trabalho por determinado tempo no processo de prestação de serviços se torna possível e sustentável apenas nesse contexto de trabalho forçado via determinação judicial. Não existe nenhum dispositivo legal orientando que a tempo para tal ato infracional é tantos meses e tantas horas. A aplicação, conforme o ECA/90, dependente da discricionariedade do juiz observando a gravidade da infração, as circunstâncias e a capacidade de cumpri-la.

O tempo, na execução dessa medida, ilude nossa percepção. Num primeiro momento, parece ser consumido com e pela instituição que consume a força de trabalho do adolescente autor de ato infracional. Mas, o tempo da força de trabalho consumido na prestação de serviços, também, é gasto no processo socioeducativo cujo o trabalho é um aspecto desse, já

\footnotetext{
${ }^{16}$ Segundo Liberati (2006, p.369) as medidas socioeducativas possuem caráter impositivo (coercitivo) "[...] porque a medida é aplicada independentemente da vontade do infrator; é sancionatório, porque, com a ação ou omissão, o infrator quebra a regra de convivência social; é retributivo, por ser uma resposta ao ato infracional praticado".

${ }^{17}$ Em caso de descumprimento de medida socioeducativa poderá ser aplicado a internação-sanção prevista no art. 122, inciso III do ECA/90.
} 
que que o homem ao transformar "[...] a natureza externa, modifica sua própria natureza" (MARX, 1994, p.202). Num segundo momento, o tempo da medida não deixa transparecer que além dele existe outro, o tempo do sujeito. O tempo institucional/objetivo não é o tempo do sujeito/adolescente para "ressignificação de valores na vida pessoal e social" (RESOLUÇÃO $\mathrm{N}^{\circ}$ 09,2009, p. 24), bem como o rompimento com a prática de atos infracionais.

A sincronia entre eles, raramente ou quase nunca, acontecer na prática, uma vez que “[...] o tempo de cada adolescente responder de forma eficaz à medida não é predeterminado, ainda que o tempo da medida o seja" (METODOLOGIA DE BH, 2010, p. 28). Tal descompasso fez Santana (2009) observar que “[...] as interações vivenciadas durante o cumprimento da medida sócio-educativa [de PSC] podem ser vistas como um processo de socialização secundária" (SANTANA,2009, p. 04), contudo uma socialização bem frágil pelo pouco tempo que os adolescentes permanecem no programa.

Esse tempo subjetivo/jurídico está intrinsecamente ligado a responsabilização jurídica/subjetiva sendo nada mais que o tempo necessário para realização de cada uma respectivamente. Logo abaixo estuda-se como se efetiva a responsabilização jurídica/subjetiva por meio do trabalho na medida de Prestação de serviços à Comunidade.

\section{O Trabalho Enquanto Ação Educativa}

O debate sob a natureza pedagógica das medidas socioeducativas divide a opinião de teóricos, porém não é uma discussão nova. Na medida de Prestação de Serviços à Comunidade vários estudiosos abordaram esse tema: Ataíde (2002), Prates (2012), Silva (2009) e outros, não obstante suas nuances ainda se encontram obscuras. Além disso, o tratamento ao tema vem sendo marcado muito mais por enganos do que por acertos como veremos a abaixo.

Ao invés de questionar se a medida de Prestação de serviços à Comunidade (PSC) possui caráter educativo ou punitivo busca-se entender o caráter pedagógico do trabalho a partir daquilo que os autores, estudados até aqui, compreendem como trabalho educativo. Para captar o trabalho como instrumento pedagógico e de responsabilização deve-se em primeiro lugar apreender a medida de PSC como processo socioeducativo do qual o trabalho é constituinte e constituidor. Somente assim teremos mais clareza do aspecto educativo do trabalho nessa medida. 
A medida de PSC é uma das expressões do processo socioeducativo no qual o adolescente autor de ato infracional é inserido. Processo esse constituído por duas principais dimensões entrelaçadas e vinculadas entre si. A responsabilização e a educação são as dimensões determinantes desse processo socioeducativo. A interação e existência simultânea entre tais dimensões confere dinamismo e movimento ao processo, portanto a medida é movimento, é processo de ajustamento de conduta e subjetivação de determinada sociabilidade.

De acordo com Teixeira (2006, p.32) “[...] responsabilização significa impor resposta, determinar resultado como consequência jurídica de uma conduta" etiquetada como ato infracional. A concepção de responsabilização na Metodologia de Belo Horizonte (2010), aplicada as medidas socioeducativas de meio-aberto, se divide em responsabilização jurídica e responsabilização subjetiva. A primeira, diz da resposta do Estado ao ato infracional cometido pelo adolescente, ou seja, a "[...] passagem pelo sistema judiciário pressupõe o advento da responsabilidade jurídica, uma vez que instaura uma relação entre a ação transgressora e o sancionamento efetuado pela instância jurídica representada pelo Estado" (METODOLOGIA DE BH, 2010, p. 31).

Por outro lado, a responsabilização subjetiva diz da resposta elaborada pelo adolescente frente a responsabilização jurídica. A Metodologia de $\mathrm{BH}$ não define a responsabilização subjetiva, mas coloca que:

São indicadores de responsabilização subjetiva quando as respostas frente à ordem
judicial alcançam questões significativas relacionadas à forma de relacionamento do
adolescente com os membros de sua comunidade, a disposição dos vínculos
familiares, o seu envolvimento com o processo educativo e profissional, o modo
como concebe sua vida e suas escolhas sociais e afetivas (METODOLOGIA DE
BH, 2010, p. 34).

A partir desses indicadores pode-se inferir que responsabilização subjetiva é a internalização de valores sociais e normas de convivência legitimadas socialmente ${ }^{18}$. Somente, nessa perspectiva que, por exemplo, participar de curso profissionalizante pode indicar ou sinalizar responsabilização subjetiva.

Muitas vezes, embora o adolescente se responsabilize juridicamente cumprindo a carga horária de trabalho “[...] isso pode não ser suficiente para que o adolescente mude de

\footnotetext{
${ }^{18}$ Para Marx e Engles (2006, P.78) “[...] as ideias (Gedanken) da classe dominante são, em todas as épocas, as ideias dominantes, ou seja, a classe que é a força material dominante da sociedade é, ao mesmo tempo, sua força espiritual dominante. A classe que dispõe dos meios de produção material dispõe também dos meios de produção espiritual, o que faz com que sejam a ela submetidas, ao mesmo tempo, as ideias daqueles que não possuem os meios de produção espiritual".
} 
posição diante de seus atos ou se responsabilize subjetivamente pelos mesmos" (METODOLOGIA DE BH, 2010, p. 31). Costa \&Alípio (2010, p. 211), nesse sentido, observam que "[...] para alguns [adolescentes] este trabalho se coloca somente como o cumprimento de uma determinação judicial. Para outros, o trabalho proposto pela medida tem realmente um valor de ressignificação de sua vida".

Evidencia-se, assim, que entre a responsabilização jurídica e a subjetiva existe um interstício, uma lacuna. O preenchimento dessa lacuna necessário para a passagem da responsabilização jurídica para a subjetiva só pode ser pensada (ou possível) a partir da dimensão educativa da medida que atuará como instrumento de mediação. Essa passagem não se efetiva ou materializa em um mundo abstrato, pelo contrário, efetiva-se no mundo do homem real que trabalha em determinadas instituições.

Desta forma, essa transição se dá nas instituições por meio da ação humana, mas não se efetiva em uma única instituição sendo formado por diferentes instituições (Poder Judiciário, serviço de execução, instituições parceiras e outros) e atores sociais (policiais, juízes, promotores, assistentes sociais, psicólogos, educadores de referência e outros) constituidores e operadores dessa medida socioeducativa. Essas instituições/atores sociais constitui um todo orgânico socioeducativo no qual a interação entre essas instituições/atores sociais não acontece sem antagonismos, ora afirmando determinados procedimentos e concepções, ora negando-os ou sintetizando-os, mas a síntese não encerra tais antagonismos sendo esses que conferem mudanças e movimento ao todo orgânico socioeducativo.

A responsabilização e a ação pedagógica, nessas instituições, existem simultaneamente não sendo possível separá-las nem saber quando uma termina e outra começa. Além disso, assumem formas e níveis distintos de acordo com a instituição/ator social na qual se efetivam. Em uma audiência, por exemplo, a responsabilização terá mais peso que a dimensão educativa o que não significa a anulação do aspecto educativo, pelo contrário, a audiência é em si uma ação educativa na vida do adolescente.

Nesse processo socioeducativo as instituições sem fins lucrativos, que consumirá a força de trabalho do adolescente, é o principal lócus para efetivação da responsabilização e da ação pedagógico na medida de PSC. Ao cumprir a carga horária de trabalho determinada judicialmente e, consequentemente, responsabilizar-se juridicamente pelos seus atos o adolescente interage com a instituição, seus funcionários e, por conseguinte, nessa interagiração humaniza-se, socializa-se ao compartilha normas e regras de convivência com os trabalhadores daquela instituição. A natureza educativa do trabalho, desta forma, media a transição da responsabilização jurídica para subjetiva. Mas afinal, o que seria, na medida 
socioeducativa de PSC, um trabalho com cunho educativo?

Na bibliografia localizada não encontrei resposta para tal questão apenas afirmações: Silva (2009) salienta que os adolescentes desenvolvem como principais atividades “[...] limpeza, organização de fichários, atender ao telefone, algumas se constituem em atividades pontuais e mecânicas que não possuem um cunho educativo e não aprimoram conhecimentos" (SILVA, 2009, p.93). Nas palavras de Ataíde (2002, p. 88) “[...] os jovens, que cumpriam a medida de prestação de serviços à comunidade, eram submetidos a trabalhos onde não havia um cunho socioeducativo subjacente à medida". De acordo com Prates (2012, p.134) "[...] as opções de trabalho são restritas e pouco educativas. As tarefas, via de regra, são mecânicas e exigem pouco raciocínio". Para o autor as atividades, na maioria das vezes, estão ligadas a serviços gerais e questiona suas possibilidades pedagógicas.

Ambos, assim como outros autores, não distinguem um trabalho pedagógico de outro punitivo nem explicam o que faz um ser educativo e o outro não. No entanto, pode-se deduzir que a concepção de trabalho educativo para esses estudiosos nasce da dicotomia entre trabalho intelectual/material presente, principalmente, nas sociedades capitalistas as quais supervalorizam o trabalho intelectual em detrimento do trabalho material. Logo, o trabalho intelectual é considerado educativo por possibilitar ao adolescente o aprendizado de habilidades novas, aperfeiçoar a mão de obra e desenvolver suas capacidades cognitivas enquanto, por outro lado, o trabalho material pela natureza mecânica, repetitivo e desgaste físico é considerado não educativo e, logo punitivo. Essa forma de pensamento levou esses autores a atribuir caráter pedagógico ou punitivo ao trabalho dependendo da atividade desempenhada pelo adolescente dentro da instituição. Somente a partir desse raciocínio que Prates (2002) poderia questiona as possibilidades educativa das atividades vinculadas aos serviços gerais.

Essa linha de raciocínio desvirtua a natureza pedagógica do trabalho dentro da medida de PSC ao adotar um ponto de vista valorativo e econômico para explica-lo. Com isso, ignoraram que a medida não busca a formação de mão de obra qualificada e não existe um trabalho totalmente manual ou intelectual, mas todo trabalho é uma combinação orgânica desses. Se esse ponto de vista estivesse correto os adolescentes cumpririam a carga horária determinada judicialmente desenvolvendo suas capacidades cognitivas por meio da realização de cursos profissionalizantes e qualificação de mão de obra para inserção no mercado de trabalho.

Tal distorção aparece em duas instituições responsáveis pela execução da medida de PSC no interior do Estado do Paraná pesquisadas por de Miyagui (2008). Em uma delas 
vinculada a uma entidade católica o cumprimenta da medida era operacionalizada "[...] por meio da participação em cursos profissionalizantes" (MIYAGUI, 2008, p. 120). Nas palavras de Ane (entrevistada pela autora) isso é colocado assim: “[...] eu achei que ia trabalhar aqui, e eu tô fazendo curso que tem um aprendizado melhor, uma educação melhor" (MIYAGUI, 2008, p. 110). As atividades profissionalizantes até fazem parte da medida (SINASE/2012), mas como secundárias e complementares.

Para avançarmos no debate, temos que adotar um outro ponto de vista e observar o objeto de um outro ângulo. Para isso, temos que deslocar a compreensão do caráter pedagógico fechado no trabalho em si e da educação voltada para inserção no mercado de trabalho para educação enquanto processo de socialização que se assenta nas relações sociais construídas com e pelo trabalho. Na verdade, a natureza educativa do trabalho na medida de PSC se encontra, justamente, nessas relações sociais, ao invés, na dicotomia entre trabalho intelectual/material como muitos pesquisadores imaginaram.

Nessa perspectiva, ao trabalhar o ser humano não só produz mercadorias ou presta serviços, mas também estabelece relações sociais e, consequentemente, desenvolvem habilidades sociais, aprendem e internalizam normas de convivência, valores, em fim essas relações sociais (re) produzem uma determinada forma histórica de pensar, agir e viver em sociedade. Desta forma, a dimensão pedagógica do trabalho, embora isso aconteça de forma secundário, não se refere a qualificação profissional, apropriação de conhecimento para inserção no mercado de trabalho ou "[...] oportunizar que adolescentes em PSC vivenciem uma experiência positiva de trabalho" (SANTANA, 2009, p.55), ao contrário, diz respeito a experiência de convivência social e ao aprendizado para o convívio social sem quebrar normas e regras etiquetadas como ato infracional. Costa (2006), nesse sentido, destaca que:

\footnotetext{
A natureza essencial da ação socioeducativa é a preparação do jovem para o convívio social. A escolarização formal, a educação profissional, as atividades artístico-culturais, a abordagem social e psicológica de cada caso, as práticas esportivas, a assistência religiosa e todas as demais atividades dirigidas ao socioeducando devem estar subordinadas a um propósito superior e comum: desenvolver seu potencial para ser e conviver, isto é, prepará-lo para relacionar-se consigo mesmo e com os outros, sem quebrar as normas de convívio social tipificadas na Lei Penal como crime ou contravenção (COSTA, 2006, p. 449).
}

Todo trabalho comunitário, nessa linha de pensamento, é educativo, uma vez que possibilita o estabelecimento de relações sociais. Logo, a dimensão socializadora do trabalho adquire condições concretas de existência na inter-relação humana não no trabalho em si sendo esse somente um meio não um fim em si mesmo como supôs vários autores até hoje. 


\title{
Considerações Finais
}

A produção de conhecimento referente à medida de Prestação de Serviço à Comunidade (PSC) ainda é incipiente. Com raras exceções, os estudiosos dessa área pesquisaram questões e problemáticas comuns a todas as medidas socioeducativas até hoje. Estudaram a existência imediata da PSC enquanto forma genérica das medidas socioeducativas, mas não o que distingue a PSC das outras medidas ou lhe atribui características especificas.

O trabalho nessa medida, não só a diferencia das outras, mas também lhe atribui características próprias. Embora, ocupe lugar central nessa medida, uma vez que configura sua forma de ser no mundo jurídico e na sociedade, ainda tem sido tratado de forma secundário pela literatura especializada. A abordagem da categoria trabalho, como demonstrado acima, cada vez mais mostra-se de suma importância para compreensão dos mecanismos socioeducativos que operam na medida de PSC.

Por fim, uma grande parte dos estudiosos das medidas socioeducativas indagaram se a medida de PSC possui um caráter educativo ou meramente punitivo por meio da colocação do adolescente para trabalhar. Mas, uma outra pergunta, talvez, ainda mais relevante cabe ser feita: afinal, o caráter pedagógico do trabalho comunitário busca a subjetivação de quais padrões sociais de conduta? Tal medida seria uma forma de disciplinamento da classe trabalhadora para o trabalho assalariado?

\section{LABOUR CENTRALITY THE EXTENT TO COMMUNITY SERVICE SOCIOEDUCATIVA}

\begin{abstract}
In this paper, we intend to understand and explain the centrality of the work category in the measure of Community Service Provision (CPS). The study, based on exploratory and inserted in the field of theoretical research, presents, initially, a critical analysis of the specialized national literature. Later, from the Marxist thought, it reflects under the centrality of the work in the measure of PSC. Finally, it analyzes how the educational character of this measure is effective through work. Based on the research, it is shown that the work distinguishes the measure of PSC from other socio-educational measures, configuring its peculiar way of being in the legal and social field.
\end{abstract}

Keywords: Socio-educational measures. Labor. Provision of community service. 


\section{TRABAJO CENTRALIDAD LA MEDIDA EN SOCIOEDUCATIVA SERVICIO A LA COMUNIDAD}

\section{Resumèn}

En este trabajo, tenemos la intención de comprender y explicar la centralidad de la categoría de trabajo a partir de Servicios a la Comunidad (PSC). El estudio, con la base exploratoria y se inserta en el campo de la investigación teórica presenta inicialmente un análisis crítico de la literatura nacional especializado. Más tarde, desde el pensamiento marxista, refleja bajo la centralidad del trabajo en la medida PSC. Por último, se analiza tan eficaz, a través del trabajo, el carácter educativo de esta medida. Basado en la investigación demuestra que el trabajo se distingue medida PSC de otras medidas educativas ajuste su modo peculiar de ser en el ámbito jurídico y social.

Palabras clave: Medidas socioeducativas. El trabajo. La prestación de servicios a la comunidad.

\section{Referências:}

ATAIIDE, M.A. Um cidadão brasileiro: o adolescente autor de ato infracional e a medida socioeducativa de Prestação de Serviços à Comunidade. Dissertação (mestrado em Serviço Social). Pontifícia Universidade Católica de São Paulo, São Paulo, 2002.

BRASIL. Estatuto da Criança e do Adolescente, lei federal, 8.069/1990, de 16 de setembro de 1990. Diário Oficial da República Federativa do Brasil, Poder Executivo, Brasília, 1990.

- Ministério de Desenvolvimento Social e Combate à Fome. Política Nacional de Assistência Social (PNAS). Brasília: Secretaria Nacional de Assistência Social, 2004.

Tipificação nacional de serviços socioassistenciais. Resolução n. 109, de 11 de novembro de 2009. Brasília: MDS/CNAS, 2009.

Sistema Nacional de Atendimento Socioeducativo. Lei federal, 12.594/2012 de 18 de janeiro de 2012. Diário Oficial da República Federativa do Brasil, Poder Executivo, Brasília, 2012.

Secretaria de Direitos Humanos da Presidência da República. Medidas socioeducativas em meio aberto: a experiência de Belo Horizonte, 2010. Vol. 1. Metodologia. Belo Horizonte: Santa Clara, 2010.

COSTA, Antônio Carlos Gomes. Execução das medidas socioeducativas em meio aberto: prestação de serviços à comunidade e liberdade assistida. In: ILANUD; ABMO; SEDH; UNFPA (orgs). Justiça, Adolescente e Ato Infracional: socioeducação e responsabilização. São Paulo: ILANUD, 2006.

COSTA, R. P. \& Alípio, S. Trabalho compulsório? O sentido do trabalho para os jovens que cumprem a Medida de Prestação de Serviço à Comunidade - PSC, Pesquisas e Práticas Psicossociais, São João Del-Rei, 4 (2), p. 205-212, jul. 2010.

CRAIDY, Carmen Maria; GONÇALVES, Liana Lemos. Medidas sócio-educativas: da 
repressão à educação; a experiência do Programa de Prestação de Serviços à Comunidade Federal do Rio Grande do Sul. Porto Alegre: Editora da UFRGS, 2005.

FERREIRA, Luiz Antônio Miguel. Execução das medidas socioeducativas em meio aberto: prestação de serviços à comunidade e liberdade assistida. In: ILANUD; ABMO; SEDH; UNFPA (orgs). Justiça, Adolescente e Ato Infracional: socioeducação e responsabilização. São Paulo: ILANUD, 2006.

FLORES, Paula Santos. Oficina Socioeducativa: Oficina com Adolescentes em Medidas Socioeducativas. Dissertação de Mestrado. Porto Alegre: Universidade Federal do Rio Grande do Sul. Faculdade de Educação. Programa de Pós-Graduação da Faculdade de Educação, 2011.

FREITAS, C.N. O Serviço Social e a medida socioeducativa de prestação de serviço à comunidade em Sobradinho (DF). Trabalho de conclusão de curso de Serviço Social. Universidade de Brasília: Instituto de Ciências Humanas, 2014.

GOBBO, Edenilza; MULHER, Crisna Maria. Possibilidades e limites da efetivação do caráter sociopedagógico da medida de prestação de serviços à comunidade cumprida por adolescente autores de ato infracional do município de São Miguel do Oeste, Espaço Jurídico, Joaçaba, vol.10, no 2, p. 315-338, jul./dez. 2009.

GONÇALVES, Liana Lemos. A vez e a voz de adolescentes em Prestação de Serviços à Comunidade na UFRGS: ato infracional e educação. Dissertação de Mestrado. Porto Alegre: Programa de Pós-Graduação em Educação/FACED, Universidade Federal do Rio Grande do Sul, 2002.

HARNECKER, Marta. Os Conceitos Elementais do Materialismo Histórico. 6.ed. Rio de Janeiro: Global, 1971.

LIBERATI, Wilson Donizete. Execução das medidas socioeducativas em meio aberto: prestação de serviços à comunidade e liberdade assistida. In: ILANUD; ABMO; SEDH; UNFPA (orgs). Justiça, Adolescente e Ato Infracional: socioeducação e responsabilização. São Paulo: ILANUD, 2006.

MARX, Karl. Economia. Paul Singer (org.); Tradução de Edgard Melagori et al. São Paulo: Ática, 1982.

. O fetichismo da mercadoria: seu segredo. In: O capital. São Paulo: Betrand Brasil, 1994. p. 79-93; p. 201-223.

A Ideológica Alemã. São Paulo: Cortez, 2006.

O Capital. Crítica da economia política (Tomo 2, Cap. XIII a XXV). São Paulo: Nova Cultural, 1996.

Cultural, 978.

Manuscritos econômicos-filosóficos e outros textos. 2.ed. São Paulo: Abril Trabalho estranhado e propriedade privada; A relação da propriedade privada; 
Propriedade privada e trabalho. In: Manuscritos econômico-filosóficos. São Paulo: Boitempo, 2004.

MEIRELlES, D. S. O conceito de serviço, Revista de Economia Política, São Paulo, v. 26, $\mathrm{n}^{\mathrm{o}} 1$ (101), pp. 119-136, jan./mar. 2006.

MIYAGUI, Camila. $O$ adolescente e a medida socioeducativa de prestação de serviços à comunidade. Dissertação de Mestrado. São Paulo: Pontifícia Universidade Católica de São Paulo; Programa de Pós-Graduação em Psicologia Social, 2008.

OIT (Organização Internacional do Trabalho). Convenção sobre o trabalho forçado ou obrigatório. Convenção n. 29 de 28 de junho de 1930.

PRATES, Flávio Cruz. Adolescente infrator: a prestação de serviços à comunidade. Curitiba: Juruá, 2012.

PÔSSA, H. A. A. P. A medida socioeducativa na agenda da rede municipal de educação de Belo Horizonte: a escola como local de prestação de serviço à comunidade. Dissertação de Mestrado. Belo Horizonte: Centro Universitário UMA; Programa de Mestrado em Gestão Social, Educação e Desenvolvimento Local, 2013.

SANTANA, Liliane Szczepanski. A medida socioeducativa de prestação de serviço à comunidade: um estudo de caso em uma unidade de execução. Trabalho de conclusão de curso. Porto Alegre: Universidade Federal do Rio Grande do Sul, Instituto de Filosofia e Ciências Humanas, Curso de Ciência Sociais: Bacharelado, 2009.

SANTOS, Ilza de Carvalho. Entre os direitos negados e atendidos: adolescentes em conflito com a lei na prestação de serviço à comunidade em Goiânia. Dissertação de Mestrado. Goiânia; Pontifícia Universidade Católica de Goiás, 2009.

SILVA, J. L. TORRES, M. M. O perfil dos adolescentes que cumprem medida socioeducativa de prestação de serviços à comunidade em Maringá - PR. Revista de Serviço Social, Londrina, v. 14, n. 1, p. 198-221, jul./dez., 2011.

SILVA, Luana Gleyce Souza. Adolescência e violência: um estudo da medida socioeducativa de prestação de serviço à comunidade no município do Natal. Dissertação de Mestrado. Natal: Universidade Federal do Rio Grande do Norte; Programa de PósGraduação em Serviço Social, 2009.

SILVEIRA, Silvania Dellamora. Matizes das significações do ato infracional da adolescente feminina em cumprimento de medida socioeducativa no programa de PSCprestação de serviço à comunidade da UFRGS- Universidade Federal do Rio Grande do Sul. Dissertação de Mestrado. Porto Alegre: Universidade Federal do Rio Grande do Sul; Programa de Pós-Graduação em Educação, 2005.

TEIXEIRA, Maria de Lourdes Trassi. Execução das medidas socioeducativas em meio aberto: prestação de serviços à comunidade e liberdade assistida. In: ILANUD; ABMO; SEDH; UNFPA (orgs). Justiça, Adolescente e Ato Infracional: socioeducação e responsabilização. São Paulo: ILANUD, 2006. 
VITAL, C.G. A Educação Social na Medida Sócio-Educativa de Prestação de Serviço à Comunidade: urna experiência em grupo. Trabalho de Conclusão de Curso (Graduação em Serviço Social). Florianópolis: Universidade Federal de Santa Catarina; Curso de Serviço Social, 2005.

Data de recebimento: $25 / 05 / 2015$

Data de aceite: 26/06/2017

\section{Sobre o autor:}

José Edson Martins é Assistente Social na Unidade Prisional de Abaeté. Bacharel em Serviço Social pela Universidade do Estado de Minas Gerais - Unidade de Abaeté. Endereço eletrônico: joseedsonm@ hotmail.com 